\title{
Capítulo II - Diagnóstico e classificação da gravidade
}

O diagnóstico da asma deve ser baseado em condições clínicas e funcionais e na avaliação da alergia(1-4).

\section{Diagnóstico Clínico}

São indicativos de asma:

- um ou mais dos seguintes sintomas: dispnéia, tosse crônica, sibilância, aperto no peito ou desconforto toráci$\mathrm{co}$, particularmente à noite ou nas primeiras horas da manhã

- sintomas episódicos

- melhora espontânea ou pelo uso de medicações específicas para asma (broncodilatadores, antiinflamatórios esteróides)

- diagnósticos alternativos excluídos

Perguntas que devem ser formuladas aos pacientes (ou pais) para se estabelecer o diagnóstico clínico de asma:

- tem ou teve episódios recorrentes de falta de ar (dispnéia)?

- tem ou teve crises ou episódios recorrentes de chiado no peito (sibilância)?

- tem tosse persistente, particularmente à noite ou ao acordar?

- acorda por tosse ou falta de ar?

- tem tosse, sibilância ou aperto no peito após atividade física?

- apresenta tosse, sibilância ou aperto no peito após exposição a alérgenos como mofo, poeira domiciliar e animais ou a irritantes como fumaça de cigarro e perfumes ou após resfriados ou alterações emocionais como riso ou choro?

- usa alguma medicação quando os sintomas ocorrem? com que freqüência?

- há alívio dos sintomas após o uso de medicação?

\section{Diagnóstico funcional}

\subsection{ESPIROMETRIA}

São indicativos de asma ${ }^{(1,2,5,6)}$ :

- obstrução das vias aéreas caracterizada por redução do $\mathrm{VEF}_{1}$ (inferior a $80 \%$ do previsto) e da relação $\mathrm{VEF}_{1} / \mathrm{CVF}$ (inferior a 75 em adultos e a 86 em crianças)

- obstrução ao fluxo aéreo que desaparece ou melhora significativamente após uso de broncodilatador (aumento do $\mathrm{VEF}_{1}$ de $7 \%$ em relação ao valor previsto e $200 \mathrm{ml}$ em valor absoluto, após inalação de $\beta_{2}$ de curta duração); limitação ao fluxo aéreo sem resposta ao broncodilatador em teste isolado não deve ser interpretado como obstrução irreversível das vias aéreas
- aumentos espontâneos do $\mathrm{VEF}_{1}$ no decorrer do tempo ou após uso de corticosteróides (30 a 40mg/dia vo, por duas semanas) de $20 \%$, excedendo $250 \mathrm{ml}$

\subsection{Pico do fluxo expiratório (PFe)}

A variação diurna exagerada do PFE pode ser utilizada para documentar a obstrução variável do fluxo aéreo.

São indicativos de asma(4,7):

- diferença percentual média entre a maior de três medidas de PEF efetuadas pela manhã e à noite com amplitude superior a $20 \%$ em um período de duas a três semanas

- aumento de $20 \%$ nos adultos e de $30 \%$ nas crianças no PFE, 15 minutos após uso de $\beta_{2}$ de curta duração(8)

\subsection{Testes adicionais}

Em indivíduos sintomáticos com espirometria normal e ausência de reversibilidade demonstrável ao uso de broncodilatador, o diagnóstico pode ser confirmado pela demonstração de hiper-responsividade das vias aéreas:

- teste de broncoprovocação com agentes broncoconstritores (metacolina, histamina, carbacol) com alta sensibilidade e alto valor preditivo negativo $0^{(9,10)}$

- teste de broncoprovocação por exercício demonstrando queda do $\mathrm{VEF}_{1}$ acima de $10 \%$ a $15 \%(10,11)$.

\section{Diagnóstico da alergia}

A anamnese cuidadosa é importante para a identificação de prováveis alérgenos, podendo ser confirmados por provas in vivo (provas cutâneas) ou in vitro (determinação de concentração sanguínea de IgE específica):

- testes cutâneos devem ser realizados utilizando-se extratos biologicamente padronizados; a técnica mais utilizada é a de puntura. Em nosso meio predominam os antígenos inaláveis, sendo os mais freqüentes os ácaros das espécies Dermatophagoides pteronyssinus e Blomia tropicalis.

- outros alérgenos inaláveis (pólen, baratas, epitélio de gatos e cães) têm menos importância. Alimentos raramente induzem asma.

- a determinação de IgE sérica específica confirma e complementa os resultados dos testes cutâneos, fornecendo dados quantitativos, mas, por ser mais onerosa, não tem sido recomendada rotineiramente ${ }^{(12)}$.

\section{Diagnóstico diferencial}

Algumas condições são específicas das diferentes faixas etárias. 0 Quadro 1 resume as que mais freqüente- 
QUADRO 1

Diagnóstico diferencial

Anel vascular

Apnéia obstrutiva do sono

Aspergilose broncopulmonar alérgica

Bronquiectasias

Bronquiolites

Carcinoma brônquico

Discinesia da laringe

Disfunção de cordas vocais

D oença respiratória crônica da prematuridade

DPOC

Embolia pulmonar

Fibrose cística
Fístula traqueoesofágica

Incoordenação da deglutição

Infecções virais e bacterianas

Insuficiência cardíaca

M assas hipofaríngeas

Massas mediastinais

O bstrução alta das vias aéreas

O bstrução mecânica das vias aéreas

Refluxo gastroesofágico

Síndrome de Loeffler

Síndrome de hiperventilação

\begin{tabular}{|c|c|c|c|c|}
\hline \multicolumn{5}{|c|}{$\begin{array}{c}\text { Q U ADRO } 2 \\
\text { Classificação da gravidade da asma }\end{array}$} \\
\hline & Intermitente & Persistente leve & Persistente moderada & Persistente grave \\
\hline $\begin{array}{l}\text { Sintomas } \\
\text { falta de ar, aperto } \\
\text { no peito, chiado } \\
\text { e tosse }\end{array}$ & $\leq 1 \mathrm{vez} /$ semana & $\begin{array}{l}\geq 1 \mathrm{vez} / \text { semana } \\
\text { e }<1 \mathrm{vez} / \mathrm{dia}\end{array}$ & $\begin{array}{l}\text { Diários } \\
\text { mas não contínuos }\end{array}$ & $\begin{array}{l}\text { Diários } \\
\text { contínuos }\end{array}$ \\
\hline Atividades & $\begin{array}{c}\text { Em geral normais } \\
\text { Falta ocasional ao } \\
\text { trabalho ou } \\
\text { escola }\end{array}$ & $\begin{array}{l}\text { Limitação para } \\
\text { grandes esforços } \\
\text { Faltas ocasionais } \\
\text { ao trabalho ou } \\
\text { escola }\end{array}$ & $\begin{array}{l}\text { Prejudicadas } \\
\text { Algumas faltas ao } \\
\text { trabalho ou escola. } \\
\text { Sintomas com } \\
\text { exercício moderado } \\
\text { (subir escadas) }\end{array}$ & $\begin{array}{l}\text { Limitação diária } \\
\text { Falta freqüente ao } \\
\text { trabalho e escola. } \\
\text { Sintomas com } \\
\text { exercícios leves, } \\
\text { (andar no plano) }\end{array}$ \\
\hline Crises* & $\begin{array}{c}\text { O casionais (leves) } \\
\text { Controladas com } \\
\text { broncodilatadores, } \\
\text { sem ida à } \\
\text { emergência }\end{array}$ & $\begin{array}{l}\text { Infreqüentes } \\
\text { Algumas } \\
\text { requerendo curso } \\
\text { de corticóide }\end{array}$ & $\begin{array}{c}\text { Freqüentes } \\
\text { Algumas com ida à } \\
\text { emergência, uso de } \\
\text { corticóides sistêmicos } \\
\text { ou internação }\end{array}$ & $\begin{array}{l}\text { Freqüentes - graves } \\
\text { N eccessidade de } \\
\text { corticóide sistêmico, } \\
\text { internação ou com } \\
\text { risco de vida }\end{array}$ \\
\hline $\begin{array}{l}\text { Sintomas } \\
\text { notumos** }\end{array}$ & $\begin{array}{c}\text { Raros } \\
\leq 2 \text { vezes/mês }\end{array}$ & $\begin{aligned} & 0 \text { casionais } \\
> & 2 \text { vezes/mês e } \\
\leq & 1 \text { vez/semana }\end{aligned}$ & $\begin{array}{c}\text { Comuns } \\
>1 \text { vez/semana }\end{array}$ & $\begin{array}{l}\text { Q uase diários } \\
>2 \text { vezes/semana }\end{array}$ \\
\hline $\begin{array}{l}\text { Broncodilatador } \\
\text { para alívio }\end{array}$ & $\leq 1 \mathrm{vez} /$ semana & $\leq 2$ vezes/semana & $\begin{array}{l}>2 \text { vezes/semana e } \\
<2 \text { vezes/dia }\end{array}$ & $\geq 2$ vezes/dia \\
\hline $\begin{array}{l}\text { PFE ou VEF } \\
\text { nas consultas }\end{array}$ & $\begin{array}{c}\text { Pré-bd }>\mathbf{8 0} \% \\
\text { previsto }\end{array}$ & $\begin{array}{l}\text { Pré-bd } \geq \mathbf{8 0} \% \text { ou } \\
\text { previsto }\end{array}$ & $\begin{array}{c}\text { Pré-bd entre } 60 \% \text { e } \\
80 \% \text { previsto }\end{array}$ & $\begin{array}{c}\text { Pré-bd }<60 \% \\
\text { previsto }\end{array}$ \\
\hline
\end{tabular}


mente podem ser confundidas com asma e que devem ser consideradas no diagnóstico diferencial.

\section{Classificação da gravidade}

A asma pode ser classificada quanto à gravidade em intermitente e persistente leve, moderada e grave.

Estima-se que $60 \%$ dos casos de asma sejam intermitentes ou persistentes leves, $25 \%$ a $30 \%$ moderados e $5 \%$ a $10 \%$ graves. Os asmáticos graves são a minoria, mas representam a parcela maior em utilização de recursos.

\section{ReferÊnCiAs}

1. NAEP Expert Panel Report II. Guidelines for the diagnosis and management of asthma. NHLBI Info Center, Bethesda, Maryland, 1997.

2. Siersted HC, Mostgaard G, Hyldebrandt N, Hansen HS, Boldsen J, Oxhoj $\mathrm{H}$. Interrelationship between diagnosed asthma, asthma like symptoms, and abnormal airway behavior in adolescence: the 0 dense Schoolchild Study. Thorax 1996; 51:503-9.

3. Sociedade Brasileira de Pneumologia e Tisiologia. II Consenso brasileiro no manejo da asma. J Pneumol 1998;4:173-276.

4. The Canadian Asthma Consensus Group (eds). Canadian asthma consensus report. CMAJ 1999;161:S1-62.

5. American Thoracic Society. Lung function testing: selection of reference values and interpretative strategies. Am Rev Respir Dis 1991; 144:1202-18.

6. Sociedade Brasileira de Pneumologia e Tisiologia. I Consenso brasileiro sobre espirometria. J Pneumol 1996;22:105-64.

7. Quanjer PH, Lebowitz MD, Gregg I, Miller MR, Pedersen OF. Peak expiratory flow: conclusions and recommendations of a Working Party
A avaliação usual da gravidade da asma pode ser feita pela análise da freqüência e intensidade dos sintomas e pela função pulmonar. A tolerância ao exercício, a medicação necessária para estabilização dos sintomas, o número de visitas ao consultório e ao pronto-socorro, 0 número anual de cursos de corticosteróide sistêmico, 0 número de hospitalizações por asma e a necessidade de ventilação mecânica são aspectos também utilizados para classificar a gravidade de cada caso(13).

No Quadro 2 são apresentados os principais parâmetros para classificação da gravidade da asma.

of the European Respiratory Society. Eur Respir J 1997;10(Suppl 24):28.

8. Gibson PG, Wlodarczyk J, Hensley MJ, Murree-Allen K, Olson LG, Saltos N. Using quality-control analysis of peak expiratory flow recordings to guide therapy for asthma. Ann Intern Med 1995;123:488-92.

9. Cockcroft DW, Killian DN, Mellon JJA, Hargreave FE. Bronchial reactivity to inhaled histamine: a method and clinical survey. Clin Allergy 1997; 7:235-43.

10. Sterk PJ, Fabbri LM, Quanjer PH, Cockcroft DW, O'Byrne PM, Anderson SD, et al. Airway responsiveness. Standardized challenge testing with pharmacological, physical and sensitizing stimuli in adults. Eur Respir J 1993;6(Suppl 16):53-83.

11. Kumar A, Busse WW. Recognizing and controlling exercise-induced asthma. J Respir Dis 1995;16:1087-96.

12. Busse WW, Lemanske RF. Asthma. N Engl J Med 2001;344:350-62.

13. Cockcroft DW, Swystum VA. Asthma control versus asthma severity. J Allergy Clin Immunol 1996;98:1016-8. 